\title{
NOISE CITRA DAN ESTIMASI DOSIS RADIASI DENGAN AKTIFASI SISTEM AUTOMATIC EXPOSURE CONTROL PADA PEMERIKSAAN COMPUTED TOMOGRAPHY KEPALA
}

\section{IMAGE NOISE AND ESTIMATION OF RADIATION DOSE WITH AUTOMATIC EXPOSURE CONTROL ACTIVATED ON HEAD COMPUTED TOMOGRAPHY EXAMINATION}

\author{
Rini Indrati ${ }^{1)}$, Azlan Yazid $^{2)}$, Bagus Abimanyu ${ }^{3)}$ \\ ${ }^{1,3)}$ Health Polytechnics of Semarang-Indonesia \\ 2) Technologist in Dr. Moewardi Surakarta Hospital \\ e-mail: riniindrati@poltekkes-smg.ac.id
}

\begin{abstract}
Background: Of the ways to maintain optimum image quality and reduce the intensity of radiation to patients is optimizing the value of tube current (mAs) using parameter of Automatic Exposure Control (AEC) or mA modulation. But at the fact in hospital, protocol parameter Automatic Exposure Control (AEC) is not activated or OFF on head computed tomography examination.

Methods: This study was a quatitative experimental study. Subject of this study was head phantom. Phantom scanned with four treatments, the activation parameters was sure exp.3D-high quality, sure exp.3D-standard, sure exp.3D-low dose and AEC-OFF. Noise was analyzed using the standard deviation of the CT Number. The ROI of approximately $5 \mathrm{~mm}^{2}$ the intracranial area which is divided into three quadrants namely the anterior region, central region and posterior region of neck which is uniform are aof phantom.

Results: The results showed significant differences when parameter automatic exposure control was activated and disabled or AEC-OFF with $\mathrm{p}$ value was $0.003(<0,05)$. Furthermore, based on the scanning results in a change of radiation dose estimation to the highest doses value of the activation parameters of automatic exposure control and the lowest dose when parameter automatic exposure control deactivated or AECOFF.

Conclusion: Activation parameters of automatic exposure control (sure exp. 3D) on a head CT examination image noise tends to decline and give a higher radiation dose than when parameter automatic exposure control deactivated or AEC-OFF.
\end{abstract}

Keyword: Image Noise, Dose Estimates, Automatic Exposure Control, Head Computed Tomography

\section{PENDAHULUAN}

Tujuan utama dari setiap departement radiologi diagnostik adalah secara konsisten menghasilkan kualitas citra yang optimal. Untuk memenuhi tujuan tersebut, pengaturan parameter scanning untuk, menghasilkan kualitas citra yang optimal sangat diperlukan, terutama pengaturan arus tabung $(m A)$ dan waktu exposure $(s)$ yang berhubungan dengan banyaknya intesitas sinar-X yang diterima oleh detektor.

Pengaturan parameter scanning dapat mempengaruhi kualitas citra dan dosis radiasi. Sebagian besar parameter scanning dapat dimodifikasi untuk mendapatkan kualitas citra yang diinginkan dengan dosis radiasi minimum yang diterima oleh pasien. Kualitas citra dan dosis radiasi selalu terhubung satu sama lain, yang berarti bahwa memodifikasi kualitas citra memiliki efek terhadap dosis radiasi dan kualitas citra CT. Meskipun ada hubungan terbalik antara noise dan dosis radiasi, beberapa penelitian telah menunjukkan bahwa informasi diagnostik dapat dicapai dengan pengurangan dosis yang cukup besar (Kalra dkk 2004).

Pengaturan parameter scanning sangat penting untuk diketahui mengingat bahwa dalam setiap pemeriksaan adanya variasi ukuran dan komposisi daerah anatomi yang mempengaruhi kualitas citra dan intensitas radiasi. Komposisi pasien sangat berpengaruh terhadap kualitas citra, karena adanya perbedaan attenuasi jaringan pada tubuh. Misalnya, pada jaringan tulang dan paru-paru masing-masing memiliki tingkat attenuasi jaringan yang berbeda. Hal ini mempengaruhi intensitas sinar- $X$ pada detektor yang mempengaruhi tingkat noise pada citra digital. (Keat.N, 2005). Akurasi pengukuran attenuasi oleh detektor tergantung dari intensitas sinar-X. Ketika foton sinar-X yang terdeteksi relatif sedikit, tingkat akurasi pengukuran attenuasi lebih kecil, sehingga citra yang direkonstruksi dari data ini akan memiliki noise yang lebih tinggi. Dalam pemeriksaan Computed Tomography, untuk meningkatkan kualitas citra akan berhubungan dengan peningkatan dosis radiasi terhadap pasien, sehingga diperlukan pengaturan protokol pemeriksaan yang optimal untuk menyeimbangkan peningkatan kualitas citra dan penuruna dosis radiasi yang dikeluarkan.

Karena meluasnya penggunaan Computed Tomography (CT) sebagai alat pencitraan diagnostik maka CT menjadi sumber radiasi utama dibidang kesehatan yang menimbulkan bahaya paparan radiasi terhadap pasien. Resiko kanker dari sinar-X diagnostik dilaporkan dari 0,6\% meningkat menjadi 3,0 \% dinegara maju (Baskan, dkk 2015).

Radiasi yang terkait dengan sebagian besar pemeriksaan diagnostik $C T$ umumnya menggunakan paparan radiasi dosis rendah, namun yang menjadi perhatian adalah adanya efek stokastik yang mengarah kekarsinogenis akibat radiasi.Efek 
stokastik tidak memiliki batas ambang bawah dengan demikian seberapapun dosis yang diberikan walaupun kecil biasa berhubungan dengan efek ini (Kalra dkk, 2006), sehingga yang menjadi fokus saat ini adalah menjaga dosis radiasi yang diterima oleh tubuh serendah mungkin.

Dosis radiasi akan sebanding dengan jumlah foton dan energi foton dalam berkas sinar-X, salah satu cara yang dapat dilakukan untuk menjaga kualitas citra tetap optimal dan mengurangi dosis radiasi terhadap pasien yaitu dengan mengoptimalkan nilai arus tabung (mAs). Optimalisasi arus tabung dapat dilakukan dengan menggunakan parameter Automatic exposure control (AEC) atau $m A$ modulation. Automatic Exposure Control mengacu pada teknik yang memungkinkan penyesuaian secara otomatis arus tabung pada bidang $\mathrm{x}, \mathrm{y}$ (angular modulation), sepanjang $\mathrm{z}$-axis (longitudinal modulation), atau keduanya (combined modulation). Perubahan arus tabung dilakukan sesuai dengan ukuran bentuk masing-masing pasien dan kemampuan atenuasi dari bagian tubuh yang dipindai. Operator Computed Tomography dapat memilih tingkat kualitas gambar yang diperlukan dan kemudian sistem dapat menyesuaikan arus tabung untuk mendapatkan kualitas gambar yang telah ditentukan dengan meningkatkan efisiensi radiasi (Kalra, dkk 2005).

Sistem $A E C$ sangat penting untuk mengoptimasi kualitas citra dan dosis radiasi terhadap pasien yang menjalani pemeriksaan Computed Tomography. Teknik ini menggunakan radiografi localizer untuk menentukan ukuran pasien dan daerah redaman (attenuation) yang menyesuaikan kualitas citra dengan arus tabung.Tubuh dengan tingkat attenuasi yang lebih tinggi di-scan dengan menggunakan arus tabung (mili ampere) yang tinggi dibandingkan dengan daerah tubuh dengan tingkat pelemahan atau attenuasi yang lebih rendah.

Pada setiap $C T$-scan telah memiliki berbagai protokol yang telah diprogram untuk jenis pemeriksaan yang berbeda, dengan pengaturan nilai tegangan tabung, arus tabung, waktu rotasi, lebar slice, dll. Pengaturan parameter umumnya ditetapkan berdasarkan "rata-rata" ukuran pasien. Radiografer dapat melakukan variasi parameter ini pada setiap pasien, biasanya melalui modifikasi arus tabung atau waktu rotasi dengan mengubah nilai $m A s$ (tube current - time product). Pasien dengan postur tubuh yang besar akan membutuhkan $m A s$ yang tinggi untuk meningkatkan tingkat atenuasi dan ini juga akan meningkatkan noise citra. Begitu pula pada pasien anak-anak, akan menunjukkan kualitas gambar yang optimal dengan menurunkan nilai $m A s$ sesuai kebutuhan pasien.

Perubahan parameter scanning tergantung pada instansi rumah sakit, tetapi dalam banyak kasus itu diserahkan kepada penilaian radiografer. Salah satu cara yang paling efektif adalah dengan menyesuaikan nilai arus tabung untuk pasien yang berbeda ukuran berdasarkan karakteristik dari pasien seperti tinggi badan, berat badan, indeks massa tubuh, atau ukuran tubuh pasien (AAPM Rpt.96, 2008).

Computed Tomography scanner yang modern dilengkapi dengan berbagai fitur teknis, yang berfungsi untuk mengurangi paparan radiasi. Salah satu fitur yang paling penting adalah automated exposure control (AEC). Automated Exposure Control berkerja dengan cara menyesuaikan keluaran arus tabung dan dosis radiasi berdasarkan diameter dan tingkat attenuasi dari objek yang discanning (Becker et al 2011).

Pengaturan nilai arus tabung adalah merupakan bagian dari optimasi protokol. Penggunaan $A E C$ yang menyesuaikan nilai $m A$ yang digunakan. Untuk memastikan kualitas gambar diatur dengan benar adalah dengan menggunakan image noise level, refence $m A$ s pada saat pengaturan AEC (AAPM RPT.96 2008). Setiap jenis alat memiliki sistim automatic exposure control yang berbeda. Sistem automatic exposure control pada tiap pabrikan Computed Tomography dapat dilihat pada tabel

Tabel 1. Sistem atomatic exposure control pada beberapa pabrikan Computed Tomography

\begin{tabular}{lll}
\hline Pabrikan & \multicolumn{1}{c}{ Sistem AEC } & \multicolumn{1}{c}{$\begin{array}{c}\text { Pengaturan Tingkat } \\
\text { Kualitas Citra }\end{array}$} \\
\hline Siemens & CARE Dose 4D & Quality reference mAs \\
Philips & DoseRight & Reference image \\
GE & Auto mA 3D & Noise index \\
Toshiba & Sure Exposure 3D & Image quality level/standard \\
& & deviation
\end{tabular}

Cara terbaik untuk mengeahui dosis pasien dari penggunaan system $A E C$ adalah dengan melihat indikator dosis pada monitor Computed Tomography scan. Semua scanner modern saat ini telah menampilkan secara rutin nilai Computed Tomography Dose Index (CTDIvol) dan Dose Length Product (DLP) untuk setiap pemeriksaan. Dengan memantau parameter ini sebelum dan setelah penggunaan $A E C$, dampaknya terhadap dosis radiasi pada setiap pemeriksaan dapat dinilai dengan baik (AAPM RPT.96 2008).

Pada beberapa klinis tertentu seperti pemeriksaan thorax dan abdomen sistem $A E C$ secara optimal dapat mengurangi dosis terhadap pasien sekitar 20-40\% dan menghasilkan kualitas citra yang menunjang diagnosis (McCollough, 2005). Penelitian sebelumnya telah menunjukkan pengurangan dosis radiasi yang cukup besar dan peningkatan kualitas citra dengan menggunakan teknik $A E C$ pada pasien anak-anak dan dewasa (Kalra, dkk 2004). Pada beberapa rumah sakit pada protokol Computed Tomography head parameter automatic exposure control dalam kondisi OFF atau dinonaktifkan. Mengingat pada pencitraan Computed Tomography head mata yang sering terpapar oleh radiasi primer (primary $x$-ray beam) (Becker, 2011). Beberapa organ lain juga rentan terhadap radiasi seperti otak.

Tujuan dari penelitian ini adalah untuk mengetahui perbedaan noise citra dan perubahan dosis radiasi ketika sistem automatic exposure control (AEC) diaktifkan dan dinonaktifkan pada pemeriksaan computed tomography head, dengan menggunakan sistem automatic exposure control pabrikan Computed Tomography Toshiba Medical System. 


\section{METODE}

Penelitian ini menggunakan desain studi eksperimental dengan menggunakan metode kuantitatif. Penelitian ini menggunakan head phantom sebagai subyek penelitian. Head phantom ditempatkan dalam posisi supine dengan midline sagital dan mid-thickness phantom tepat berada pada isocenter gantry. Phantom discanning dengan menggunakan Multi Slice Computed Tomography scanner 64-slice (Aquilion 64; Toshiba Medical System, Tokyo, Jepang), dengan parameter scanning seperti pada tabel 2 .

Tabel 2. Parameter Scanning Head Protocol

\begin{tabular}{ll}
\hline Setting & Head Protocol \\
\hline Scan mode & Helical \\
Collimation & $0.5 \times 32$ \\
Pitch & Detail \\
kV & 120 \\
Ma & 300 \\
Rotation time(s) & 0.75 \\
Total scan time(s) & 19.8 \\
Range(mm) & 250 \\
DireComputed Tomographyion & OUT \\
D-FOV & $220.3(\mathrm{~S})$ \\
CE & OFF \\
\hline
\end{tabular}

Phantom di scanning dengan pengaktifan parameter automatic exposure control (Sure Exp. 3D) dengan pengaturan high quality, standard, low dose dan OFF.

\section{Pengukuran Noise Citra dan Dosis Radiasi}

Noise citra diukur dengan menggunakan standar deviasi dari $C$ Tnumber yang dilakukan dengan membuat ROI sebesar $5 \mathrm{~mm}^{2}$ pada daerah intracranial yang dibagi kedalam tiga kuadran yaitu anterior region, central region dan posterior region pada daerah neckyang merupakan daerah uniform pada phantom (Gambar 1). Selanjutnya dilakukan analisis noise / standar deviasi terhadap sepuluh irisan yang berdekatan sepanjang arah sumbu z.

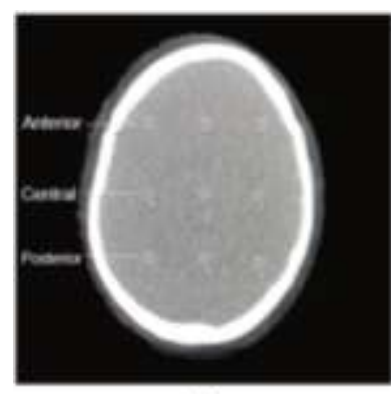

(a)

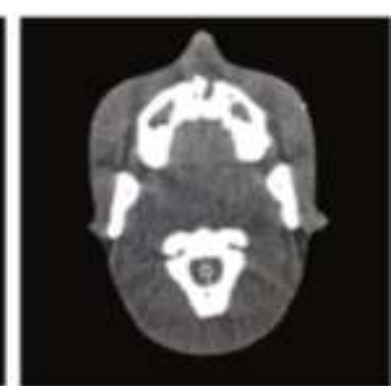

(b)
Gbr. 1. Penempatan Region of Interst (ROI) pada citra hasil scanning head phantom (a) daerah intracranial (b) daerah neck

Rata-rata noise pada tiap kelompok juga dicatat dan dibandingkan pada tiap parameter automatic exposure control yang berbeda.

Estimasi dosis radiasi akibat perubahan parameter automatic exposure control diaktifkan dan dinonaktifkan dicatat dengan melihat nilai CTDI $_{\mathrm{vol}}$ dan nilai DLP (Dose
Length Product). Dari nilai-nilai DLP dapat dilakukan estimasi perubahan dosis relatif dengan menghitung perubahan nilai DLP ketika parameter automatic exposure control diaktifkan dan dinonaktifkan.

Analisis data dilakukan dengan Analysis of variance (Anova) dengan tingkat signifikasi $95 \%$.Analisis diskriptif digunak an untuk menggambarkan adanya perubahan estimasi dosis radiasi ketika parameter automatic exposure control diaktifkan dan dinonaktifkan pada pemeriksaan computed tomography head. Hasil analisis data dari estimasi dosis radiasi ini kemudian digambarkan dalam bentuk tabel.

\section{HASIL}

Studi penelitian ini menggunakan head phantom sebagai subyek penelitian dalam melakukan eksperimen untuk mengetahui perbedaan noise citra dan dosis radiasi ketika mengaktifkan dan menonaktifkan parameter automatic exposure control (AEC) / $\mathrm{mA}$ modulation pada pemeriksaan computed tompography head menggunakan pesawat Computed Tomography scan Toshiba 64-slice. Pengaturan parameternya dibagi menjadi empat perlakuan, yaitu Aktifasi parameter Sure Exp.3D-High Quality, Aktifasi parameter Sure Exp.3D-Standard, Aktifasi parameter Sure Exp.3D-Low Dose, Non aktifasi parameter automatic exposure control (AEC $\mathrm{OFF}$ ) dengan arus tabung (mAs) diatur konstan.

Analisis noise citra pada 10 slice pada daerah intracranial dan daerah neck pada tiap parameter dilakukan dengan mengukur nilai standar deviasi CT number pada beberapa daerah intracranial.

Berdasarkan hasil pengukuran, nilai noise citra pada anterior region, central region, posterior region dan neck region relatif sama ketika parameter automatic exposure control diaktifkan. Sedangkan ketika sistem automatic exposure control dinonaktifkan noise citra cenderung mengalami peningkatan, seperti terlihat pada tabel 3 .

Tabel 3. Noise Citra pada Pengaktifan dan penonaktifan parameter automatic exposure control

\begin{tabular}{lclccl}
\hline \multirow{5}{*}{ Parameter } & \multicolumn{5}{c}{ Noise } \\
\cline { 2 - 6 } & $\begin{array}{c}\text { Anterior } \\
\text { Region }\end{array}$ & $\begin{array}{c}\text { Central } \\
\text { Region }\end{array}$ & $\begin{array}{c}\text { Posterior } \\
\text { Region }\end{array}$ & $\begin{array}{c}\text { Neck } \\
\text { Region }\end{array}$ & Mean \\
\hline Sure exp.3D- & $7,3 \pm 1,0$ & $7,7 \pm$ & $7,8 \pm 0,9$ & $6,8 \pm$ & $7,4 \pm$ \\
High Quality & & 1,1 & & 0,8 & 0,5 \\
Sure exp.3D- & $7,5 \pm 0,9$ & $8,1 \pm$ & $7,8 \pm 0,9$ & $6,5 \pm$ & $7,5 \pm$ \\
Standard & & 0,9 & & 0,5 & 0,7 \\
Sure exp.3D- & $7,4 \pm 0,9$ & $7,8 \pm$ & $7,6 \pm 1,3$ & $6,8 \pm$ & $7,4 \pm$ \\
Low Dose & & 1,2 & & 0,6 & 0,4 \\
AEC OFF & $7,8 \pm 1,3$ & $8,2 \pm$ & $8,1 \pm 0,9$ & $8,1 \pm$ & $8,1 \pm$ \\
& & 0,8 & & 0,9 & 0,1 \\
\hline
\end{tabular}

Parameter automatic exposure control nilai rata-rata noise citra yang dihasilkan relatif sama. Pada pengaktifan sure exp.3D high quality nilai rata-rata noise citra pada anterior region, central region, posterior region dan neck region yang dihasilkan adalah 7,4, sure exp.3D standar nilai yang dihasilkan adalah 7,5, dan sure exp. $3 D$ low dose nilai yang dihasilkan adalah 7,4. Ketika sistem automatic exposure 
control dinonaktifkan atau $A E C O F F$ nilai noise citra cenderung mengalami peningkatan dengan nilai rata-rata 8,1 .

Untuk mengetahui perbedaan noise citra ketika mengaktifkan dan menonaktifkan parameter automatic exposure control dilakan uji beda One Way-Anova. Diperoleh hasil seperti pada tabel 4 .

Tabel 4. Perbedaan noise citra pada Aktifasi automatic exposure control

\begin{tabular}{lc}
\hline Variabel & p value \\
\hline Sure exp.3D-High Quality & \\
Sure exp.3D-Standard & 0,003 \\
Sure exp.3D-Low Dose & \\
AEC OFF & \\
\hline
\end{tabular}

Berdasarkan hasil uji beda pada interval kepercayaan 95\%, antara noise citra ketika parameter automatic exposure control diaktifkan dan dinonaktifkan. Tidak terdapat perbedaan yang signifikan pada anterior region, center region, dan posterior region, dengan nilai sig. 0,003 $(\mathrm{p}<0,05)$.

Karena terdapat peredaan yang signifikan noise citra ketika parameter automatic exposure control diaktifkan dan dinonaktifkan, maka dilakukan uji lanjut/post hoc test. Uji digunakan untuk engetahui variabel mana yang memiliki perbedaan yang signifikan menggunkan uji LSD. Diperoleh hasil seperti pada tabel 5 .

Tabel 5. Perbedaan Noise Citra Ketika Parameter Automatic Exposure Control Diaktifkan Dan Dinonaktifkan

\begin{tabular}{lc}
\hline \multicolumn{1}{c}{ Variabel } & p value \\
\hline AEC ON: & 0,240 \\
Sure exp.3D-High Quality dengan Sure exp.3D Sandard & 0,917 \\
Sure exp.3D-High Quality dengan Sure exp.3D Low Dose & 0,284 \\
Sure exp.3D-Standard dengan Low Dose & 0,001 \\
AEC OFF dengan Sure exp.3D-High Quality & 0,034 \\
AEC OFF dengan Sure exp.3D-Standard & 0,001 \\
\hline
\end{tabular}

Penelitian menunjukkan terdapat perbedaan nilai noise citra CT antara pengaktifan AEC dengan parameter sure exp.3D-high quality dengan sure exp.3D-standard dengan $p$ value 0,240. Perbandingan nilai noise citra head CT degan menggunakan pengaktifan AEC antara parameter sure exp.3D-high quality dengan sure exp.3D-low dose tidak menunjukkan adanya perbedan dengan $p$ value 0,917 . Demikian juga pada saat pengaktfan AEC dengan parameter sure exp.3D-standard dengan sure exp.3D-low dose tidak menunjukkan adanya perbedaan nilai noise citra head CT dengan $\mathrm{p}$ value 0,284 . Hasil berbeda di tunjukkan ketika melakukan perbandingan nilai noise citra head CT pada AEC pada kondisi off dengan sure exp.3D-high quality menunjukkan adanya perbedaan dengan $p$ value 0,001 . Perbandingan nilai noise citra head CT pada saat AEC non aktif dengan parameter sure exp.3D standard menunjukkan ada perbedaan dengan $\mathrm{p}$ value 0,034. Demikian pula perbandingan teknik AEC off dengansure exp.3D-low dose menunjukkan adanya perbedaan nilai noise citra head CT antar AEC pada posisi off dengan parameter automatic exposure control dinonaktifkan dengan sure exp.3D-low dose dengan $\mathrm{p}$ value 0,001

\section{Hasil Analisis Estimasi Dosis Radiasi}

Analisis nilai estimasi dosis radiasi dianalisis dengan mecatat nilai $\mathrm{CTDI}_{\text {vol }}$ dan nilai DLP (Dose Length ProduComputed Tomography) ketika parameter automatic exposure control diaktifkan dan dinonaktifkan. Nilai dosis radiasi dari scanning head phantom pada tiap parameter dapat dilihat pada tabel 5 .

Tabel 6. Estimasi Dosis Radiasi dari Scanning Head Phantom Ketika Parameter Automatic Exposure Control Diaktifkan dan Dinonaktifkan

\begin{tabular}{lcc}
\hline Parameter & $\begin{array}{c}\mathrm{CTDI}_{\mathrm{vol}} \\
(\mathrm{mGy})\end{array}$ & $\begin{array}{c}\text { DLP } \\
\left(\mathrm{mGy}{ }^{*} \mathrm{~cm}\right)\end{array}$ \\
\hline AEC ON : & & \\
Sure exp.3D-High Quality & 121,8 & 3030,6 \\
Sure exp.3D-Standard & 116,5 & 2990,9 \\
Sure exp.3D-Low Dose & 116,5 & 2795,9 \\
AEC-OFF & 80,8 & 2231,1 \\
\hline
\end{tabular}

Berdasarkan tabel 6 diatas nilai estimasi dosis radiasi pada pengaktifan parameter automatic exposure control relatif sama, sedangkan ketika parameter automatic exposure control dinonaktifkan terjadi penurunan nilai dosis radiasi. Nilai dosis tertinggi terukur ketika dilakukan pengaktifan parameter sure exp.3D-high quality dengan nilai dosis 3030,6 mGy*cm dan nilai dosis terendah ketika parameter automatic exposure control dinonaktifkan yaitu 2231,1 mGy*cm. Pada pengaktifan sure exp.3D standard nilai dosis yang dihasilkan sebesar 2990,9 $\mathrm{mGy}^{*} \mathrm{~cm}$ dan pada pengaktifan sure exp.3D low dose nilai dosis yang dihasilkan sebesar 2795,9 $\mathrm{mGy}^{*} \mathrm{~cm}$.

\section{DISKUSI}

Berdasarkan hasil penelitian ini didapatkan bahwa terdapat perbedaan noise citra yang signifikan ketika parameter automatic exposure control (AEC) diaktifkan dan dinonaktifkan. Pengaktifan parameter automatic exposure control menghasilkan nilai rerata noise citra yang lebih baik dengan dibandingkan dengan ketika parameter automatic exposure control dinonaktifkan atau AEC-OFF pada pemeriksaan computed tomography head. Hal ini sesuai dengan data pengukuran pada beberapa daerah intracranial region dan neck region. Akan tetapi pada pengaktifan parameter autmatic exposure control pada pemeriksaan computed tomography head menghasilkan intersitas dosis radiasi yang lebih tinggi dibandingkan dengan ketika automatic exposure control dinonaktifkan.

Sistem automatic exposure control dikembangkan untuk memungkinkan menyesuaikan arus tabung secara otomatis berdasarkan bentuk, ukuran, dan tingkat attenuasi untuk meningkatkan kualitas citra yang konstan.

Pengaturan arus tabung $(m A)$ berpengaruh terhadap noise citra dan intensitas radiasi. Pengaktifan parameter automatic exposure control memungkinkan penyesuaian arus 
tabung secara otomatis. Penyesuaian arus tabung dilakukan sesuai dengan ukuran bentuk tubuh dan tingkat attenuasi dari bagian tubuh yang dipindai. Operator Computed Tomography dapat memilih tingkat kualias citra yang diinginkan dan kemudian sistem akan menyesuaikan arus tabung untuk mendapatkan kualitas citra yang diperlukan dengan meningkatkan efisiensi radiasi (Kalra, dkk 2015).

Pada penelitian ini dilakukan eksperimen dengan beberapa perlakuan pada pemeriksaan Computed Tomography head menggunakan Computed Tomography scan Toshiba ketika sistem automatic exposure control diaktifkan dan dinonaktifkan yaitu pengaktifan sure exp.3D-high quality, sure exp.3D standard, sure exp. 3D low dose dan AEC-OFF.

Hasil analisis statistik dengan uji One Way-Anova pada interval kepercayaan $95 \%$ menunjukkan ada perbedaan yang signifikan (nilai $\mathrm{p}<0,05$ ) noise citra ketika parameter automatic exposure control diaktifkan dan dinonaktifkan. Hal ini disebabkan oleh pada sistem AEC seorang radiografer dapat memilih tingkat kualitas gambar yang diinginkan dengan menetapkan standar deviasi deviasi dan batas $\mathrm{mA}$ minimum dan maksimum (Soderberg, 2008), sehingga pengaturan nilai arus tabung perlu dilakukan dengan teliti dan hati-hati, karena mengurangi nilai $m A s$ dapat meningkatkan noise citra yang dapat mempengaruhi kualitas citra diagnostik. Sedangkan jika meningkatkan nilai $m A s$ dapat berpengaruh terhadap dosis radiasi yang dihasilkan.

Dari hasil analisis nilai estimasi dosis radiasi pada pengaktifan parameter automatic exposure control relatif sama, sedangkan ketika parameter automatic exposure control dinonaktifkan terjadi penurunan nilai dosis radiasi. Pada pengaktifan automatic exposure control dosis radiasi yang dihasilkan lebih tinggi yaitu ketika pengaktifan parameter sure exp.3D-high quality, sure exp.3D standard dan sure exp.3D low dose. Hal ini disebabkan oleh struktur anatomi dari kepala yang cenderung simetris dan homogen, pada sistem automatic exposure controlcenderung mengatur arus tabung lebih tinggi.

Struktur anatomi tubuh pasien sangat berperan terhadap kualitas citra, karena dapat mempengaruhi intensitas sinar-X yang ditransmisikan kedetektor. Ketika foton sinar-X yang terdeteksi sedikit, sehingga menghasilkan noise citra yang lebih tinggi . Hal ini disebabkan oleh pengaktifan parameter automatic exposure control diatur berdasarkan tingkat kualitas citra yang diinginkan dengan menetapkan nilai $\mathrm{mA}$ (atau mAs) pada protocol Computed Tomography scan mAs "referensi", yang diatur berdasarkan ukuran pasien rata-rata dan kemudian menyesuaikan nilai arus tabung ukuran panampang tubuh pasien yang discanning. Penetapan sistem referensi mAs bertujuan untuk menjaga kulitas citra tetap konstan (Keat.N, 2005).

Pada penelitian ini dilakukan experimen dengan mengaktifkan dan menonaktifkan parameter automatic exposure control dengan parameter lain dilakukan pengontrolan agar tetap konstan, maka dihasilkan pengurangan noise dan peningkatan dosis radiasi. Menurut (Kalra dkk 2004) Dengan memperhatikan kepentingan klinis dan faktor keselamatan pasien dari pengaruh radiasi pada pemeriksaan computed tomography head automatic exposure control sebaiknya tidak diaktifkan.

Optimalisasi parameter scanning perlu dilakukan yang melibatkan beberapa variabel seperti tegangan tabung, slice thickness, collimation, dan pitch. Selain itu parameter parameter reconstruksi citra juga sangat penting (Soderberg, 2008). Pada studi yang dilakukan oleh Kalra dkk:2004, pengaturan parameter scanning dapat mempengaruhi kualitas citra dan dosis radiasi. Sehingga kita dapat memonitor sebagian besar parameter ini dan memodifikasinya untuk mendapatkan kualitas citra yang diinginkan dengan dosis radiasi minimum yang diterima oleh pasien.

\section{SIMPULAN}

Berdasarkan hasil pengukuran pengaktifan automatic exposure control menghasilkan noise yang lebih baik dibandingkan dengan ketika automatic exposure control dinonaktifkan yang menunjukan nilai noise cenderung meningkat ( AEC-OFF).

Penelitian ini menunjukkan bahwa terdapat perbedaan nilai noise citra yang signifikan ketika parameter automatic exposure control diaktifkan dan dinonaktifkan dengan nilai signifikansi $0,003(<0,05)$. Berdasarkan hasil uji pos hoc pengaktifan parameter automatic exposure control, sure exp.3D-high quality dengan sure exp.3D-standard, sure exp.3D-high quality dengan sure exp.3D low dose, sure exp.3D-standard dengan sure exp.3D low dose tidak terdapat perbedaan yang bermakana, dengan nilai signifikansi berturutturut 0,$240 ; 0,917$; dan 0,284 ; sedangkan pada $A E C-O F F$ dengan sure exp.3D-high quality, AEC-OFF dengan sure exp.3D-standard, AEC-OFF dengan sure exp.3D-low dose, terdapat perbedaan yang bermakna, dengan nilai signifikansi berturut-turut 0,$001 ; 0,034$; dan 0,001 .

Pengaktifan automatic exposure control pada pemeriksaan computed tomography head memberikan dosis yang lebih tinggi dibandingkan dengan ketika parameter automatic exposure control dinonaktifkan atau AEC-OFF. Dengan nilai dosis tertinggi ketika parameter sure exp.3Dhigh quality diaktifkan yaitu $3030,6 \mathrm{mGy} * \mathrm{~cm}$, pada pengaktifan sure exp.3D-Standard nilai dosis yang dihasilkan 2990,9 $\mathrm{mGy}^{*} \mathrm{~cm}$ dan pada pengaktifan sure exp.3D-low dose nilai dosis yang dihasilkan adalah $2795,9 \mathrm{mGy} * \mathrm{~cm}$ sedangkan nilai dosis terendah ketika parameter automatic exposure control dinonaktifkan $(A E C O F F)$ yaitu $2231,1 \mathrm{mGy} * \mathrm{~cm}$.

Sehingga dengan memperhatikan kepentingan klinis dan faktor keselamatan pasien terhadap pengaruh radiasi pada pemeriksaan computed tomography head automatic exposure control sebaiknya tidak diaktifkan.

\section{DAFTAR PUSTAKA}

AAPM. 2008. The Measurement, Reporting, and Management of Radiation Dose in CT Report 96. American Association of Physicists in Medicine: New York

Baskan, O, Erol C, Ozbek H, Paksoy Y. 2015. Effect of Radiation Dose Reduction on Image Quality in Adult Head CT with NoiseSuppressing Reconstruction system with a 256 slice MDCT. http://www.ncbi.nlm.nih.gov/ pubmed/26103494 
Becker, H.C., Augart, D., Karpitschka M., at.al. 2012. Radiation Exposure and Image Quality of Normal Computed Tomography Brain Image Acquired With Automated and Organ-Based Tube Current Modulation Multiband Filtering and Iterative Reconstruction. An article in Investigative Radiology.

Kalra, MK, Maher MM, Toth TL et al. 2004. Techniques and applications of automatic tube current modulation for CT. Radiology 233:649-675.

Kalra, MK, Naz N, Rizzo SM, Blake MA. 2005. Computed tomography radiation doseoptimization: scanning protocols and clinical applications of automatic exposure control. CurrProbl Diagn Radiol 2005;34:171-181.

Kalra, MK, Saini S, Rubin GD. 2006. MDCT : From Protocols to Practice. Springer-Verlag: Italia.

McCollough, CH. 2005. Automatic exposure control in CT: are we done yet? Radiology 237:7755-756

Soderberg, M. 2008. Automatic exposure control in CT:An Investigation Between Different ManufacturersConsidering Radiation Dose and Image Quality. Medical Radiation Physics Clinical Sciences, Lund Lund University. 